\title{
The effect of desensitizing dentifrice with or without diode laser therapy in the management of dentinal hypersensitivity of teeth with Miller's Class I or Class II gingival recession
}

\author{
Chandan Pal ${ }^{1, *}$, Rahul Chopra ${ }^{2}$, Nikhil Sharma ${ }^{3}$, Siddharth Tevatia $^{4}$, Joohi Chandra $^{5}$, Swapnil Singh ${ }^{6}$ \\ ${ }^{1,6}$ PG Student, ${ }^{2}$ Associate Professor, ${ }^{3}$ Professor \& HOD, ${ }^{4}$ Private Practioner, ${ }^{5}$ Senior Lecturer, ${ }^{\mathbf{1 , 2 , 3 , 5 , 6}}$ Dept. of Periodontology, \\ I.T.S. Centre for Dental Studies and Research, Ghaziabad, Uttar Pradesh, India
}

*Corresponding Author:

Email: chand201289@gmail.com

\begin{abstract}
Introduction: Dentinal Hypersensitivity $(\mathrm{DH})$ is characterized by short, sharp pain arising from exposed dentin in response to stimuli typically thermal, evaporative, tactile, osmotic or chemical. Most common modality for treatment of DH is desensitizing dentifrices through combined use of Diode laser along with desensitizing tooth paste which has shown encouraging results. The present study evaluated and compared the efficacy of toothpaste containing $10 \%$ Strontium Chloride $\left(\mathrm{SrCl}_{2}\right)$ with or without Diode laser in the treatment of DH in the teeth with Miller's Class I or II gingival recession.

Materials and Method: The study included patients (aged 18 to 50 years) with chief complaint of dentinal hypersensitivity having Miller's Class I or Class II gingival recession. A total of 20 sites equally and randomly divided into two groups; Test group (Diode+ Sensoform ${ }^{\circledR}-\mathrm{SrCl}_{2}$ Toothpaste) and Control group (Sensoform ${ }^{\circledR}-\mathrm{SrCl}_{2}$ Toothpaste). Pre and Post treatment VAS for DH was recorded at baseline, $7,15 \& 30$ day using air blast test for both the groups.

Result: Patients in both the groups reported reduced dentinal hypersensitivity. However, DH was significantly reduced in test group as compared to control group at all the intervals as measured using Visual analogue scale (VAS). Also, the test group showed statistically significant decrease in VAS, post treatment at baseline itself.

Conclusion: Within the limitations of the present study, it can be concluded that combined use of desensitizing toothpaste $\left(\mathrm{SrCl}_{2}\right)$ and diode laser therapy can be effective in providing immediate relief from DH in patients with Miller's Class I or Class II recession.
\end{abstract}

Keywords: Diode laser, Dentinal hypersensitivity, Gingival recession, Visual analogue scale, Strontium chloride, Tactile.

\section{Introduction}

Dentinal Hypersensitivity (DH) is characterized by short, sharp pain arising from exposed dentin in response to stimuli typically thermal, evaporative, tactile, osmotic or chemical and which cannot be ascribed to any other form of dental defect or pathology. ${ }^{1}$ It is common problem associated with gingival recession, incorrect tooth brushing habits, parafunctional habits, abrasion due to brushing, dietary erosion, abnormally positioned tooth in the arch, periodontal disease, periodontal surgery, crown preparation, wasting diseases, occlusal wear and aging. ${ }^{2}$ People affected by DH show difficulties in chewing, swallowing, speech and nutritional habits. Mostly canines and pre-molars are affected but can affect incisors and molars also involving the buccal surfaces, especially the cervical area of the teeth. ${ }^{3}$

The DH mechanism explained by a combination of two theories: "Hydrodynamic Theory" (Brannstrom \& Astrom 1972) and the "Neural Theory" (Seltzer et al. 1963). The most widely accepted theory is Hydrodynamic theory. In this, sudden shift of fluid in the dentinal tubules is believed to deform mechanosensitive nerve fibers close to the odontoblastic layer by the activation of A- $\delta$ nerve fibers located in the dentinal tubules. ${ }^{4,5}$
Two chief methods of treatment of DH are tubular occlusion and blockage of nerve activity. Amongst many materials and techniques to treat $\mathrm{DH}$, few are; specific dentifrices (containing agent like strontium chloride, calcium phosphate, potassium nitrate and oxalates), laser irradiation, dentine adhesives, antibacterial agents, resin suspensions (glass ionomer cement), fluoride rinses and fluoride varnishes, dentinal adhesives, periodontal plastic surgery. ${ }^{2}$

The strontium-based toothpaste seems to block the exposed dentinal tubules and this helps prevent the movement of the fluid within the tubules in response to a sensitivity stimulus. ${ }^{6}$

Another therapeutic option for the DH is the use of high and low intensity lasers. Low intensity lasers produce a rapid action with analgesic and antiinflammatory effects, through a photomodulation process. ${ }^{7}$ On the other hand, high intensity laser (ErCr:YSGG, $\mathrm{CO}_{2}, \mathrm{Nd}: \mathrm{YAG}$ and Diode) work on dentin via photothermal effects, heating and melting the surface of the hard tissue. Not only the diode lasers act by occluding the dentinal tubules but also by depressing the nerve transmission by blocking depolarization of Cfiber afferents. ${ }^{3,8,9}$

Combined use of Diode laser along with desensitizing tooth paste has shown encouraging results. ${ }^{2,3}$ Hence, in the present study an effort has been made to evaluate and compare the efficacy of 
toothpaste containing $10 \%$ strontium Chloride $\left(\mathrm{SrCl}_{2}\right)$ with or without Diode laser in the treatment of $\mathrm{DH}$ in the teeth with Miller's Class I or II gingival recession.

\section{Materials and Method}

The present study was conducted in the Department of Periodontology and Oral Implantology, ITS- CDSR, Muradnagar. The patients(aged 18 to 50 yrs.) reporting to OPD with chief complaint of dentinal hypersensitivity having Miller's Class I or Class II gingival recession not willing to undergo periodontal plastic surgery were included for the study. 20 sites were equally and randomly divided into two groups; Test group (Diode+ Sensoform ${ }^{\circledR}-\mathrm{SrCl}_{2}$ Toothpaste) and Control group (Sensoform ${ }^{\circledR}-\mathrm{SrCl}_{2}$ Toothpaste). Patients with Chronic/debilitating disease with daily pain episodes or history of any previous treatment for hypersensitivity, taking any analgesic/sedative, any cracked tooth structure or carious lesions or restorations or non-vital tooth and active periodontal disease were excluded. VAS for DH was recorded Pre and Post treatment at baseline, $7^{\text {th }}$ day, $15^{\text {th }}$ day and $30^{\text {th }}$ day. The procedure was fully explained and informed consent was obtained from each patient. The study was approved by Institutional Ethical Committee.

\section{Pain and DH assessment}

A visual analogue scale (VAS) was used to measure DH. All the patients were asked to define their level of DH by using a VAS consisting of equal units from 0 to 10 (a line of $10 \mathrm{~cm}$ ). On this scale, 0 and 10 represented "no pain/discomfort" and "worst pain/ discomfort imaginable" respectively. Patients were asked to mark the degree of pain they experienced by directing an air blast to the exposed root surface before and after treatment of DH.

DH was assessed by means of air stimulus (60 pounds per square inch, $22^{\circ} \mathrm{C}$ ), derived from a dental syringe to the root surface for $1 \mathrm{sec}$. After this stimulus, the patients scored the pain by using the VAS. The air pressure and distance between the root surface and the tip of the air syringe were kept 2-3 mm away from surface and constant for all the cases in both pretreatment and post- treatment evaluation of $\mathrm{DH}$.

\section{Treatment}

All the patients received oral prophylaxis following which baseline DH assessment was done and the teeth were randomly assigned to test group $\left(\mathrm{SrCl}_{2}\right.$ toothpaste and diode laser) and control group ( $\mathrm{SrCl}_{2}$ toothpaste alone). Also instructions in brushing technique were given and they used standardized soft-filamented toothbrush and desensitizing toothpaste during one month of trial.

The test group was subjected to GaAlAs laser Photon Plus, Zolar co., $980 \mathrm{~nm}$ with strontium chloride applied on root surface in non-contact mode using a fiber of 320-micron diameter. Each site underwent single application of 30 seconds at baseline, $7^{\text {th }}$ day, $15^{\text {th }}$ day and $30^{\text {th }}$ day respectively. Teeth subjected to diode laser treatment were irradiated with a laser beam of $1 \mathrm{~W}$ with continuous-emission form, noncontact mode ( $2 \mathrm{~mm}$ from the surface), perpendicular to the surface with scanning movements in the region of exposed root surfaces for $30 \mathrm{sec}$.

In the control group, $10 \%$ strontium chloride toothpaste $\left(\mathrm{SrCl}_{2}\right)$ was applied on the tooth surface and only a sham laser application was done. The treatment was carried out in four sessions, at baseline, $7^{\text {th }}$ day, $15^{\text {th }}$ day and $30^{\text {th }}$ day. All patients were given $\mathrm{SrCl}_{2}$ toothpaste to be used twice daily as directed. The VAS scores were taken before and after each treatment session in both test and control groups.

\section{Statistical analysis}

All the data collected, was entered in Microsoft Excel and analyzed. The statically analysis was done by SPSS version 16 . The descriptive static mean standard deviation, median of the parameter were calculated. The normality of the data was tested by Shapiro Wilk's Test. The significance difference of the parameter between the two groups with Mann Whitney U test was done. The level of significance and confidence interval was $5 \%$ and $95 \%$ respectively.

\section{Results}

The dentinal hyper-sensitivity decreased along all times measured during the four treatment sessions in both the groups; laser along with $\mathrm{SrCl}_{2}$ toothpaste (Test Group) and $\mathrm{SrCl}_{2}$ toothpaste alone (Control Group). The mean VAS scores for DH in the test group reduced significantly at baseline, 7,15 and 30 days at post treatment follow-up. However, in control group VAS score decreased at 7 and 30 day post treatment follow up only. (Table 1). (Fig. 1)

On comparing the means of the test and control group, pre and post VAS data recorded in the four treatment sessions i.e. baseline, 7th day, 15th day, 30th day, it was found that DH was significantly reduced in test group as compared to control group at $7,15 \& 30$ day intervals. (Table 2) 
Table 1: Intra group comparison between two time intervals in a group by Wilcoxon Signed Ranks Test

\begin{tabular}{|l|l|c|c|c|c|}
\hline Group & & $\begin{array}{c}\text { Pre-Post } \\
\text { (baseline) }\end{array}$ & $\begin{array}{c}\text { Pre -Post } \\
\text { (Day 7) }\end{array}$ & $\begin{array}{c}\text { Pre-Post } \\
\text { (Day 15) }\end{array}$ & $\begin{array}{c}\text { Pre-Post } \\
\text { (Day 30) }\end{array}$ \\
\hline \multirow{2}{*}{ Test } & $\mathrm{Z}$ & -2.428 & -2.236 & -2.236 & -2.449 \\
\cline { 2 - 6 } & $\mathrm{p}$ value & $.015^{*}$ & $.025^{*}$ & $.025^{*}$ & $.014^{*}$ \\
\hline \multirow{2}{*}{ Control } & $\mathrm{Z}$ & -1.633 & -2.000 & -1.890 & -2.236 \\
\cline { 2 - 6 } & $\mathrm{p}$ value & $.102^{* *}$ & $.046^{*}$ & $.059^{* *}$ & $.025^{*}$ \\
\hline
\end{tabular}

$*$ Significant $\mathrm{p}<0.05, * *$ Not significant $\mathrm{p}>0.05$

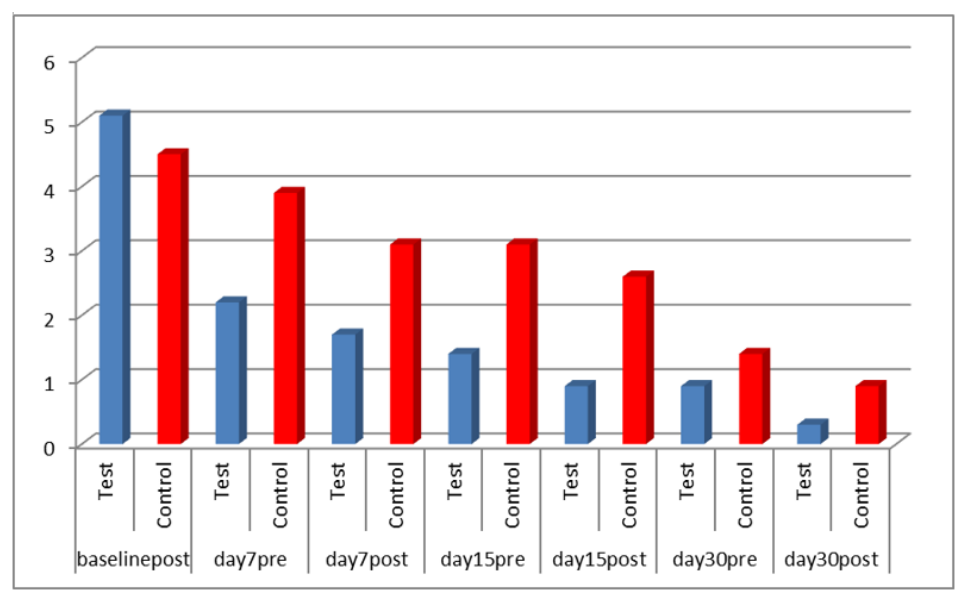

Fig. 1: Comparison of mean VAS scores in test and control group at various intervals

Table 2: Intergroup comparison of mean VAS score in test and control group $(n=20)$ at different time intervals

\begin{tabular}{|c|c|c|c|c|c|c|}
\hline & Group & $\mathbf{N}$ & $\begin{array}{c}\text { Mean } \pm \text { Std. } \\
\text { Deviation }\end{array}$ & $\begin{array}{c}\text { Mann - } \\
\text { Whitney U } \\
\text { test }\end{array}$ & $Z$ value & p value \\
\hline \multirow{2}{*}{$\begin{array}{l}\text { Pre Treatment } \\
\text { (Baseline) }\end{array}$} & Test & 10 & $6.10 \pm 2.025$ & \multirow[t]{2}{*}{32.00} & \multirow[t]{2}{*}{-1.467} & \multirow[t]{2}{*}{.142} \\
\hline & Control & 10 & $4.90 \pm 1.197$ & & & \\
\hline \multirow{2}{*}{$\begin{array}{l}\text { Post Treatment } \\
\text { (Baseline) }\end{array}$} & Test & 10 & $5.10 \pm 1.449$ & \multirow[t]{2}{*}{38.00} & \multirow[t]{2}{*}{-.985} & \multirow[t]{2}{*}{.325} \\
\hline & Control & 10 & $4.50 \pm 1.080$ & & & \\
\hline \multirow{2}{*}{$\begin{array}{l}\text { Pre Treatment } \\
\text { (Day 7) }\end{array}$} & Test & 10 & $2.20 \pm 1.229$ & \multirow[t]{2}{*}{19.50} & \multirow[t]{2}{*}{-2.357} & \multirow[t]{2}{*}{.018} \\
\hline & Control & 10 & $3.90 \pm 1.449$ & & & \\
\hline \multirow{2}{*}{$\begin{array}{l}\text { Post Treatment } \\
\text { (Day7) }\end{array}$} & Test & 10 & $1.70 \pm 1.059$ & \multirow[t]{2}{*}{16.50} & \multirow[t]{2}{*}{-2.649} & \multirow[t]{2}{*}{.008} \\
\hline & Control & 10 & $3.10 \pm .876$ & & & \\
\hline \multirow{2}{*}{$\begin{array}{l}\text { Pre Treatment } \\
\text { (Day 15) }\end{array}$} & Test & 10 & $1.40 \pm .843$ & \multirow[t]{2}{*}{9.00} & \multirow[t]{2}{*}{-3.271} & \multirow[t]{2}{*}{.001} \\
\hline & Control & 10 & $3.10 \pm .876$ & & & \\
\hline \multirow{2}{*}{$\begin{array}{l}\text { Post Treatment } \\
\text { (Day 15) }\end{array}$} & Test & 10 & $.90 \pm .738$ & \multirow[t]{2}{*}{6.00} & \multirow[t]{2}{*}{-3.473} & \multirow[t]{2}{*}{.001} \\
\hline & Control & 10 & $2.60 \pm .843$ & & & \\
\hline \multirow{2}{*}{$\begin{array}{l}\text { Pre Treatment } \\
\text { (Day 30) }\end{array}$} & Test & 10 & $.90 \pm .316$ & \multirow[t]{2}{*}{27.00} & \multirow[t]{2}{*}{-2.300} & \multirow[t]{2}{*}{.021} \\
\hline & Control & 10 & $1.40 \pm .516$ & & & \\
\hline \multirow{2}{*}{$\begin{array}{l}\text { Post Treatment } \\
\text { (Day 30) }\end{array}$} & Test & 10 & $.30 \pm .483$ & \multirow[t]{2}{*}{20.00} & \multirow[t]{2}{*}{-2.669} & \multirow[t]{2}{*}{.008} \\
\hline & Control & 10 & $.90 \pm .316$ & & & \\
\hline
\end{tabular}




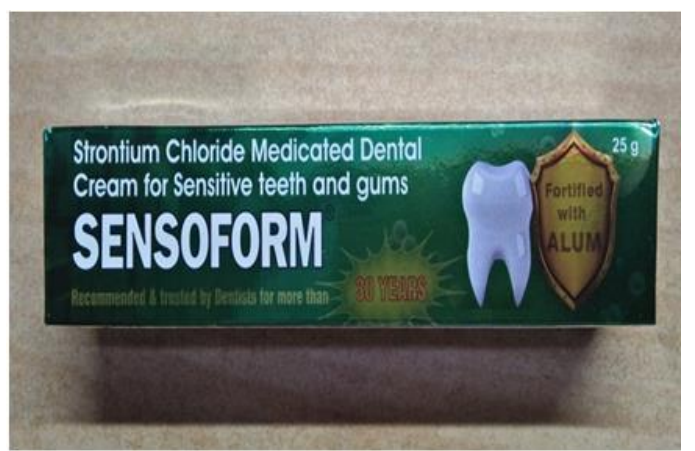

Fig. 1: Strontium Chloride $\left(\mathrm{SrCl}_{2}\right)$ tooth paste

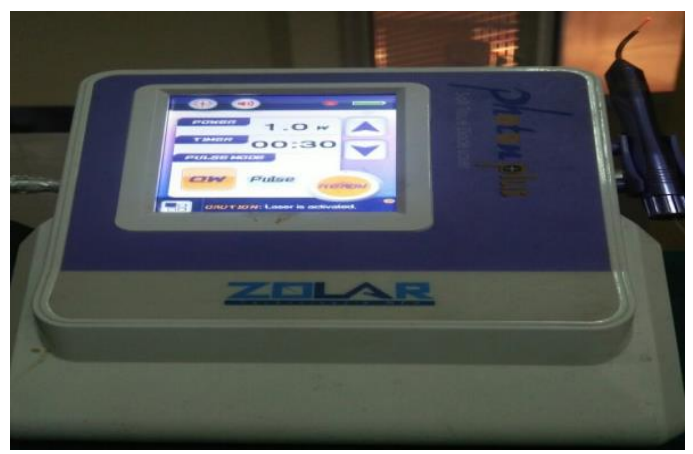

Fig. 2: Diode Laser

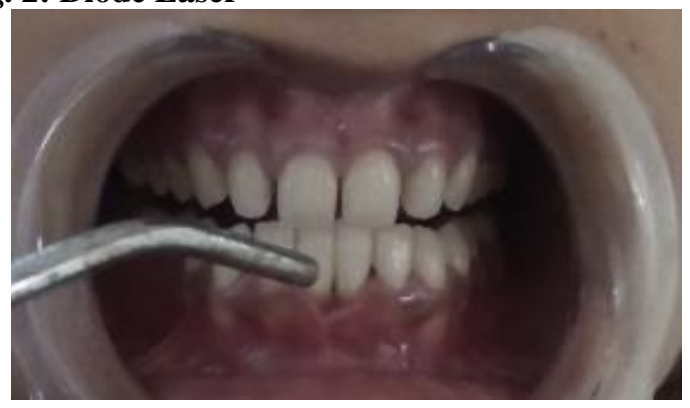

Fig. 3: Air blast test

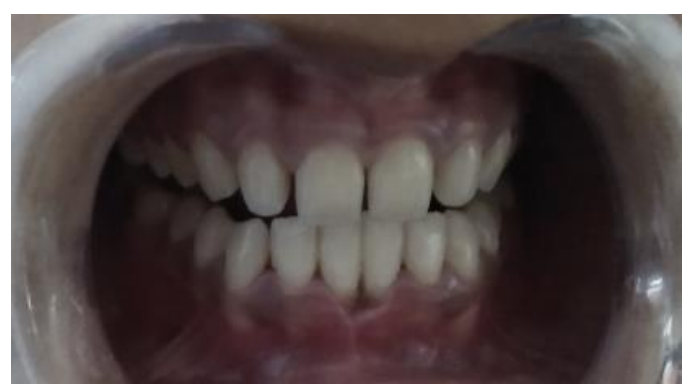

Fig. 4: Area where paste was applied

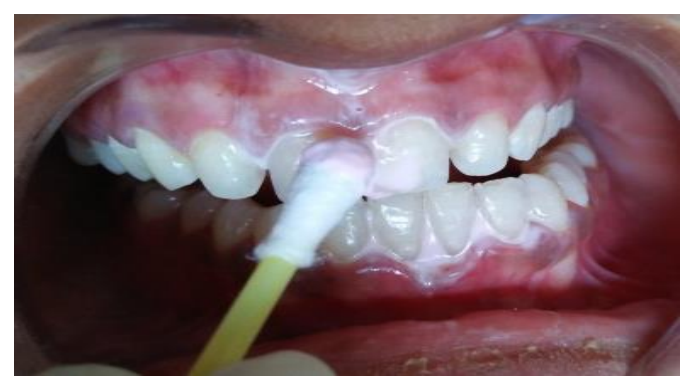

Fig. 5: Paste applied with cotton swab

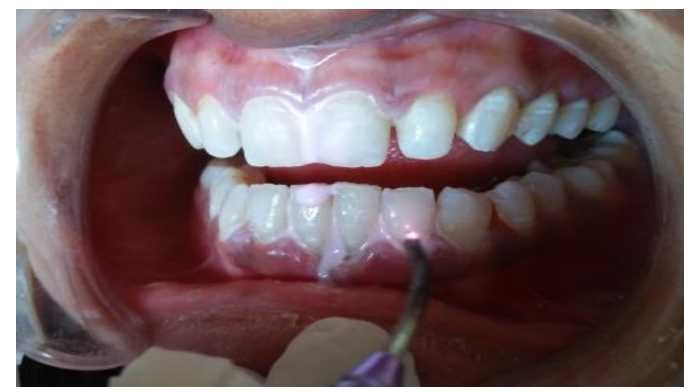

Fig. 6: Laser application w.r.t. 31, 32, 41, 42

\section{Discussion}

One of the primary causes of dentinal hypersensitivity is gingival recession as it results in exposure of dentinal tubules. The two alternative principle of dentinal hypersensitivity treatment are either blocking the nerve transmission in the pulp or by occluding the tubules to prevent the hydrodynamic mechanism in the tubules. ${ }^{10,11}$ Most of the dentifrices either work on the basis of their tubular occluding properties, for example, strontium-based (chloride and acetate) products or by nerve desensitizing, for example, potassium- based (chloride, citrate, and nitrate) products. ${ }^{12}$

In this study VAS was used to assess dentinal hypersensitivity as it has been used in previous studies by several investigators owing to its easy understanding by patients, more sensitive in discriminating between various treatments and changes in pain intensity. ${ }^{13-15}$ Among the many strategies recommended for the treatment of $\mathrm{DH}$, the use of desensitizing dentifrices is most commonly advocated. However, because the elicitation of pain in DH patients is acute, the availability of a treatment that reduces or eliminates $\mathrm{DH}$ within a period of 24-48 hours, or even earlier, would be ideal. ${ }^{16-19}$ Recently, the use of laser in treatment of DH with or without desensitizing dentifrices has gained attention. $^{5}$

On intragroup comparison, there was significant reduction in mean VAS scores in both test and control group at 7, 15 and 30 day following treatment. This was similar to results seen in study done by Dilsiz. and Sicilia. ${ }^{2,4}$

On intergroup comparison, the mean VAS score decreased significantly in test group at all the intervals including baseline post treatment. These results are in 
accordance with the study done by Dilsiz and Minkoff. ${ }^{2,6}$

The results of this study provide supportive evidence that the regular use of a dentifrice containing $10 \%$ strontium chloride hexahydrate provides an effective treatment for patients with dentinal hypersensitivity. The therapeutic response occurred within 1 week and increased with time, which could be owing to obliteration of the dentinal tubules exposed to the oral environment (Kim 1986).

The application of laser enhanced the effect of $10 \%$ strontium chloride in treating dentinal hypersensitivity as it can assist in melting dentinal tubules. ${ }^{5}$ Also, immediate relief from DH in test group at baseline post treatment can be attributed to depressed nerve transmission resulting in analgesic effects. ${ }^{20}$ Thus combined desensitization using $\mathrm{SrCl}_{2}$ along with diode laser therapy can be used to provide instant relief to patients with dentinal hypersensitivity due to Miller's Class I and Class II gingival recession.

Though the present study had certain limitations such as small sample size, absence of control group and short follow up period, it can still be concluded that both the treatment modalities are effective in providing relief from DH however the combined therapy showing immediate results.

\section{Conclusion}

Within the limitations of the present study, it can be concluded that combined desensitizing toothpaste $\left(\mathrm{SrCl}_{2}\right)$ and diode laser therapy can be effective in providing immediate relief from $\mathrm{DH}$ in patients with Miller's Class I and Class II with gingival recession.

\section{References}

1. Kimura Y, Wilder-Smith P, Yonaga K, Matsumoto K. Treatment of dentine hypersensitivity by lasers: a review. J Clin Periodontol 2000;27(10):715-21.

2. Dilsiz A, Aydın T, Emrem G. Effects of the combined desensitizing dentifrice and diode laser therapy in the treatment of desensitization of teeth with gingival recession. Photomed Laser Surg 2010; 28 Suppl 2:S69-74

3. Rosa RR, Calazans FK, Nogueira RD, Lancellotti AC, Gonçalves LS, Geraldo-Martins VR. Effects of different desensitizing treatments on root dentin permeability. Braz Oral Res 2016;30(1):111.

4. Sicilia A, Cuesta-Frechoso S, Suárez A, Angulo J, Pordomingo A, De Juan P. Immediate efficacy of diode laser application in the treatment of dentine hypersensitivity in periodontal maintenance patients: A randomized clinical trial. J Clin Periodontol 2009;36:65060.

5. Asnaashari M, Moeini M. Effectiveness of lasers in the treatment of dentin hypersensitivity. J Lasers Med Sci 2013 Winter;4(1):1-7

6. Minkoff S, Axelrod S. Efficacy of strontium chloride in dental hypersensitivity. J Periodontol 1987; 58(7):470-4.

7. Ladalardo TC, Pinheiro A, Campos RA, Brugnera Júnior A, Zanin F, Albernaz PL, Weckx LL. Laser therapy in the treatment of dentine hypersensitivity. Braz Dent J 2004;15(2):144-50.
8. Gholami GA, Fekrazad R, Esmaiel-Nejad A, Kalhori KA. An evaluation of the occluding effects of Er;Cr:YSGG, $\mathrm{Nd}$ :YAG, $\mathrm{CO}_{2}$ and diode lasers on dentinal tubules: a scanning electron microscope in vitro study. Photomed Laser Surg 2011;29(2):115-21.

9. Orchardson R, Gillam DG. Managing dentin hypersensitivity. J Am Dent Assoc 2006;137(7):990-8.

10. Orchardson R, Cadden SW.An update on the physiology of the dentine-pulp complex. Dent Update 2001; 28(4):200-6.

11. Matthews B, Vongsavan N. Interactions between neural and hydrodynamic mechanisms in dentine and pulp. Arch Oral Biol 1994; 39 Suppl. 87-95.

12. Karim BF, Gillam DG. The efficacy of strontium and potassium toothpastes in treating dentine hypersensitivity: a systematic review. Int J Dent 2013;2013:573.

13. Lan WH, Liu HC. Treatment of dentin hypersensitivity by Nd:YAG laser. J Clin Laser Med Surg 1996; 14(2):8992.

14. Corona SA, Nascimento TN, Catirse AB, Lizarelli RF, Dinelli W, Palma-Dibb RG.Clinical evaluation of lowlevel laser therapy and fluoride varnish for treating cervical dentinal hypersensitivity. J Oral Rehabil 2003;30(12):1183-9.

15. Miller PD Jr.A classification of marginal tissue recession. Int J Periodontics Restorative Dent 1985;5(2):8-10.

16. Addy M, Dowell P. Dentine hypersensitivity--a review. Clinical and in vitro evaluation of treatment agents. J Clin Periodontol 1983;10(4):351-63.

17. Dababneh RH, Khouri AT, Addy M. Dentine hypersensitivity - an enigma? A review of terminology, mechanisms, aetiology and management. Br Dent J 1999;187(11):606-11.

18. Goharkhay K, Wernisch J, Schoop U, Moritz A. Laser treatment of hypersensitive dentine: comparative ESEM investigations J Oral Laser App 2007;211-23.

19. Grossman, LI. A systemic method for the treatment of hypersensitive dentin. J Am Dent Ass 1935;22:529-602.

20. Närhi M, Kontturi-Närhi V, Hirvonen T, Ngassapa D. Neurophysiological mechanisms of dentin hypersensitivity. Proc Finn Dent Soc 1992; 88 Suppl 1:15-22. 